\title{
Microsporidial keratoconjunctivitis in a patient with AIDS
}

\author{
T W Metcalfe, R M L Doran, P L Rowlands, A Curry, C J N Lacey
}

\begin{abstract}
A male patient is described with acquired immune deficiency syndrome (AIDS) who developed chronic keratoconjunctivitis and chronic sinusitis due to infection with the microsporidian Encephalitozoon cuniculi. Diagnosis was confirmed by electron microscopic examination of conjunctival epithelial cells and nasal polypectomy specimens. Treatment with propamidine isethionate $0 \cdot 1 \%$ (Brolene) eye drops six times daily led to a prompt resolution of the keratoconjunctivitis.
\end{abstract}

Microsporidia are small obligate, intracellular, spore forming protozoal parasites. The phylum Microspora consists of approximately $\mathbf{8 0}$ genera and more than 700 species. ${ }^{\prime}$ They colonise a wide range of invertebrates and vertebrates including non-human primates though until the advent of acquired immune deficiency syndrome (AIDS) had only rarely been reported in man. ${ }^{2-5}$

\section{Case history}

A 22-year-old bisexual man was referred to the Genito-Urinary Department in 1986 having been found to be HIV antibody positive at routine screening following blood donation.

He first noticed mild ocular discomfort and blurring of vision in October 1988. His symptoms ran a chronic fluctuating course and failed to respond to several courses of topical antibiotics. He developed problems with nasal obstruction and discharge in February 1989.

He was referred to the Ophthalmology Department in June 1990. On initial examination best corrected visual acuity was $6 / 9$ in each eye.

His conjunctiva was minimally injected with no follicular or papillary response. Both corneae were diffusely covered with fine punctate epithelial opacities the majority of which stained

Hospital

T W Metcalfe

R M L Doran

Department of Ophthalmology and Genito-Urinary Medicine, General Infirmary, Leeds C J N Lacey

Department of Pathology, University of South Manchester P L Rowlands A Curry

Correspondence to: Mr T.W. Metcalfe, Eye Department, Harrogate District Hospital, Lancaste Park Road, Harrogate HG2 7SX.

Accepted for publication 26 July 1991

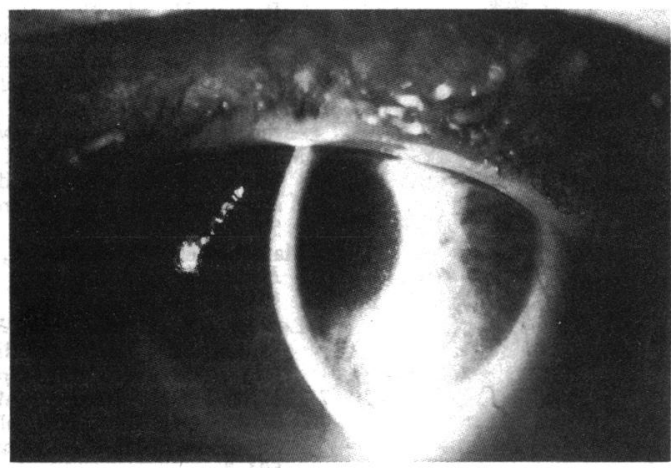

Fig $1 A$ with fluorescein (Fig 1). There was also some punctate staining of the interpalpebral bulbar conjunctiva of both eyes. The anterior chambers and vitreous were quiet and fundal examination revealed an isolated cotton wool spot above the right macula.

Similarities between this case and recent reports from the USA of microsporidial keratoconjunctivitis in patients with AIDS were noted. ${ }^{67}$

Conjunctival scrapings were therefore taken from both eyes and sent for electron microscopic examination which established the diagnosis of Encephalitozoon cuniculi keratoconjunctivitis. Formal nasal polypectomy was performed at this time to relieve the patient's chronic nasal obstruction. Histological specimens showed Encephalitozoon cuniculi infection of the surface epithelial cells of the nasal mucosa.

Treatment of the keratoconjunctivitis with guttae propamidine isethionate $0 \cdot 1 \%$ (Brolene) six times daily was begun on an empirical basis as this agent has been shown to be effective against other classes of protozoa. ${ }^{8}$

Relief of the patient's ocular symptoms and resolution of the punctate keratopathy with improvement of vision to $6 / 5$ in each eye occurred within 3 weeks of commencing therapy with propamidine isethionate. Repeat electron microscopic examination of conjunctival scrapings was carried out which failed to reveal any infected cells.

After 2 months the patient stopped using propamidine isethionate eye drops and suffered a mild recurrence of his symptoms. Clinical examination revealed a recurrence of the punctate keratoconjunctivitis and further cytological studies showed reinfection of conjunctival epithelial cells with microsporidia.

\section{Methods}

Conjunctival scrapings from both eyes and nasal

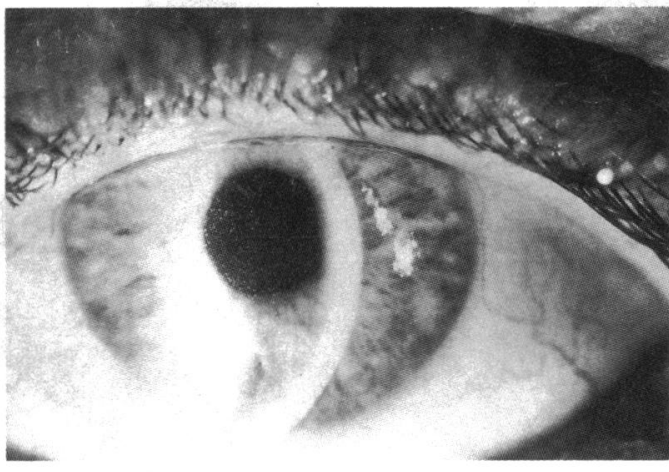

Fig $1 B$

Figure 1 Slit-lamp photograph of $(A)$ left and $(B)$ right corneae showing coarse punctate epithelial keratopathy. 
polypectomy specimens were prepared in ultrathin sections and examined in an AEI EM801 electron microscope.

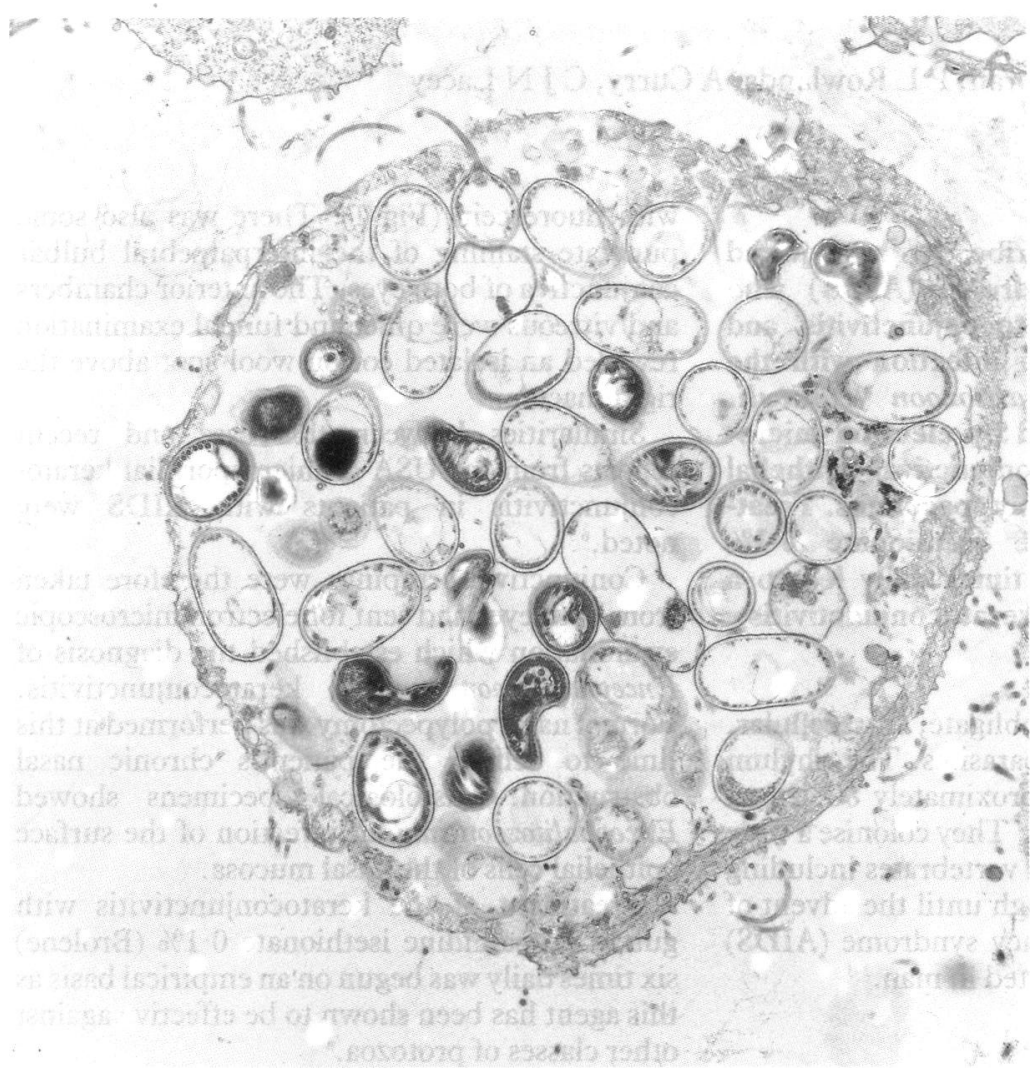

Figure 2 Electron micrograph of a conjunctival epithelial cell containing numerous Encephalitozoon cuniculi spores within membrane-bound cytoplasmic vacuoles. $(\times 5600$. $)$

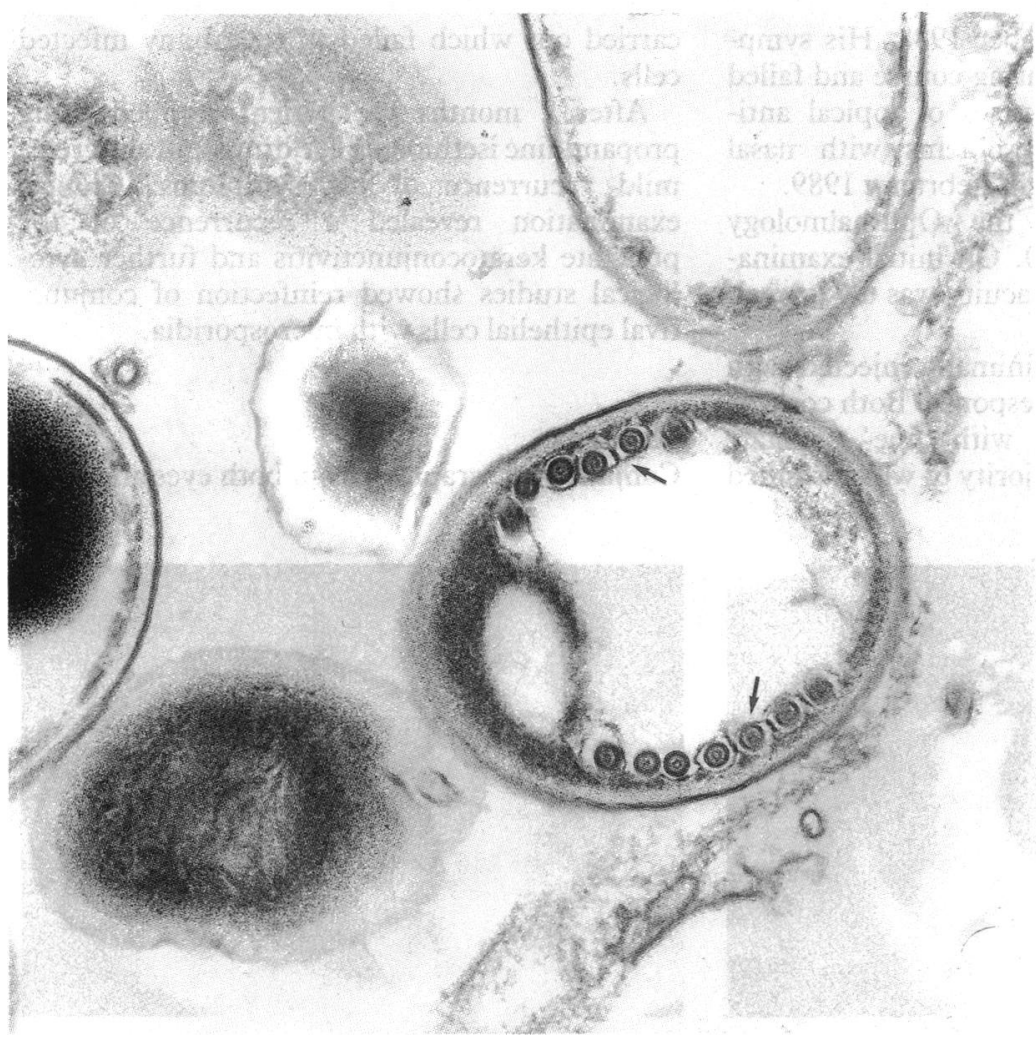

Figure 3 Electron micrograph of an Encephalitozoon cuniculi spore showing characteristic coiled filaments (arrows). ( $\times 35000$.)

\section{Results}

The conjunctival scrapings consisted of squamous epithelial cells; no inflammatory cells were seen. In the first sample the majority of epithelial cells examined from both eyes were infected with microsporidial spores contained within membrane-bound vacuoles (Fig 2). The spores were ovoid measuring $2 \mu \mathrm{m} \times 1 \mu \mathrm{m}$. The spore wall was $60 \mathrm{~nm}$ thick and comprised an outer electron dense layer (exospore) and an inner electron lucent layer (endospore). A membrane lined the endospore which in mature spores enclosed an electron dense cytoplasm. Within the cytoplasm was a single nucleus and a peripheral coiled filament which emanated from a polaroplast organelle at the anterior pole of the spore. Six or seven turns were evident in the filament (Fig 3). Extruded filaments were seen in several spores. Less mature spores were more electron lucent with fewer internal organelles. Based on these ultrastructural findings the organism was identified as Encephalitozoon cuniculi.

\section{Discussion}

The characteristic feature of AIDS is recurrent opportunistic infections in the presence of an impaired cellular immune system. Classes of organisms previously rarely seen and of low pathogenicity have become common and behave in a virulent manner. We report a man with AIDS with keratoconjunctivitis and sinusitis due to infection with the microsporidial parasite Encephalitozoon cuniculi. This is the first case of microsporidial keratoconjunctivitis in a patient with AIDS described outside the USA. Microsporidial infection of the mucosae of the nose and nasal sinuses has not previously been reported.

We found a rapid clinical improvement in this patient's keratoconjunctivitis on commencing treatment with propamidine isethionate which was confirmed by cytological studies. We suggest that further study of this antimicrobial agent whose precise mode of action is unknown is required to assess its value in patients with microsporidial infections.

Although this form of treatment holds promise for relieving ocular symptoms in this infection the likely widespread involvement of other tissues especially respiratory mucosa provides a persistent reservoir for reinfection.

1 Bryan RT. Microsporidia. In: Mandell GL, Douglas RG, Bennett JE, eds. Principles and practice of infectious diseases. 3rd edn. New York: Churchill Livingstone, 1990: 2130-4.

2 Ashton N, Wirasinha PA. Encephalitozoonosis (nosematosis) of the cornea. Br F Ophthalmol 1973; 57: 669-74

3 Pinnolis M, Egbert PR, Font RL, Winter FC Nosematosis of the cornea. Arch Ophthalmol 1981; 99: 1044-7.

4 Margileth AM, Strano AJ, Chandra R, Neafie R, Blum M, McCully RM. Disseminated nosematosis in an immunologically compromised infant. Arch Pathol Lab Med 1973; 95: 14550 .

5 Matsubayashi H, Koike T, Mikata T, et al. A case of Encephalitozoon-like body infection in man. Arch Patho $1959 ; 67: 181-7$

6 Lowder CY, Meisler DM, McMahon JT, Longworth DL, Rutherford I. Microsporidia infection of the cornea in an HIV-positive man. Am F Ophthalmol 1990; 109: 242-4

7 Freidberg DN, Stenson SM, Orenstein JM, Tierno PM, Charles NC. Microsporidial keratoconjunctivitis in acquired immunodeficiency syndrome. Arch Ophthalmol 1990; 108: immun

8 Wright P, Warhurst D, Jones BR. Acanthamoeba keratitis successfully treated medically. Br $\mathcal{F}$ Ophthalmol 1985; 69: $778-82$. 